\title{
Coexistence of adenomyosis, adenocarcinoma, endometrial and myometrial lesions in resected uterine specimens
}

\author{
SEZA TETİKKURT ${ }^{1}$, ELİF ÇELİ ${ }^{1}$, HAZAL TAŞ $^{1}$, TUĞÇE CAY ${ }^{1}$, SELMAN IŞIK $^{2}$ and ABDULLAH TANER USTA ${ }^{3}$ \\ Departments of ${ }^{1}$ Pathology, and ${ }^{2}$ Obstetrics and Gynecology, Bağcılar Training and Research Hospital, University of \\ Health Sciences, Istanbul 34200; ${ }^{3}$ Department of Obstetrics and Gynecology, Acıbadem University, Istanbul 34718, Turkey
}

Received April 5, 2018; Accepted June 12, 2018

DOI: $10.3892 / \mathrm{mco} .2018 .1660$

\begin{abstract}
The present study was conducted to identify endometrial and myometrial lesions coexisting with adenomyosis, and to evaluate the clinicopathological characteristics of endometrial adenocarcinomas associated with adenomyosis. A retrospective analysis of the resected uterine specimens of 319 patients with adenomyosis admitted between January 1, 2014 and August 1, 2017 was performed. The endometrial and myometrial lesions coexisting with adenomyosis were evaluated. The clinicopathological prognostic factors, including tumor grade, myometrial invasion, lymphovascular space involvement, lymph node invasion, pathological stage and recurrence, were analysed. For data analysis, the Chi-squared test was used and a P-value of $<0.05$ was considered to indicate statistically significant differences. The mean age of the patients was 52.1 years. A total of 32 patients had endometrial carcinoma associated with adenomyosis. In addition to endometrioid adenocarcinoma of different grades, rare clear cell carcinoma cases were also observed. Two cases of malignant mesenchymal tumors (one low-grade endometrial stromal sarcoma and one leiomyosarcoma) were also diagnosed. Therefore, patients presenting with abnormal uterine bleeding should undergo thorough evaluation for the presence of adenomyosis and/or leiomyoma(s). Although the cases of endometrial adenocarcinoma associated with adenomyosis generally had a good prognostic outcome, there were also rare cases of patients with agressive tumor morphology. The inflammatory and tissue response arising around the foci of adenomyosis generate a preventive mechanism against the invasion of adenocarcinomas coexisting with adenomyosis. This response is likely the primary mechanism underlying the good clinical course of these tumors. Therefore, the presence of
\end{abstract}

Correspondence to: Dr Seza Tetikkurt, Department of Pathology, Bağcılar Training and Research Hospital, University of Health Sciences, Dr. Sadık Ahmet Caddesi, Merkez Mahallesi, Bağcılar, Istanbul 34200, Turkey

E-mail: umitseza@gmail.com

Key words: adenomyosis, leiomyoma, endometrial adenocarcinoma, endometrioid adenocarcinoma, prognosis adenomyosis may be an important factor for the determination of prognosis.

\section{Introduction}

Adenomyosis is defined as the benign infiltration of the endometrium into the myometrium, leading to a diffusely enlarged uterus that microscopically exhibits ectopic, non-neoplastic endometrial glands and stroma, surrounded by hypertrophic and hyperplastic myometrium (1). During periods of regeneration, healing and re-epithelisation, the endometrium may invade a predisposed myometrium or a traumatised endometrial-myometrial interface. Hormonal, genetic and immunological factors may be implicated in this sequence of events (2).

Until recently, adenomyosis was retrospectively diagnosed upon histological examination of uterine specimens. The epidemiological nature of adenomyosis was well-correlated with women who had undergone hysterectomy for abnormal uterine bleeding. Among hysterectomy specimens, the reported incidence of adenomyosis in the literature varies, ranging from an incidence as high as $61.5 \%$ to as low as $8.8 \%(1,3-9)$. The histological diagnosis of adenomyosis primarily depends on the detection of endometrial glands and stroma within the myometrium, located at a distance from the endometrio-myometrial junction (10). The minimum distance mandatory for diagnosis is controversial, with a range of $2 \mathrm{~mm}$ to $>4 \mathrm{~mm}$, or 1-2 low-power fields (11). This wide discrepancy in prevalence is partially due to the difference in histological criteria used for diagnosis, and partially due to the difference in frequency of comorbidities that necessitated hysterectomy in different populations (3). Coexisting pathologies, such as leiomyoma, endometriosis, endometrial polyp, endometrial hyperplasia and endometrial carcinoma, are frequently associated with adenomyosis (12). The high incidence of these pathological lesions associated with adenomyosis suggest the presence of a common underlying disorder, such as hyperestrogenism $(1,13)$.

The presence of adenomyosis in determining the prognosis of endometrial cancer remains controversial. The aim of the present study was to evaluate the histopathological pattern of the hysterectomy specimens obtained from patients with adenomyosis presenting with abnormal uterine bleeding, endometrial carcinoma, and other causes. Another objective was to 
assess the clinical and pathological prognostic characteristics of patients with adenocarcinoma.

\section{Patients and methods}

Ethics. This is a retrospective observational cohort study. Prospective ethical approval (2017/\#604 Project) was obtained from the Human Research Ethics Commitee at the Bagcilar Training and Research Hospital. The research was conducted in accordance with the ethical standarts laid down in the 1964 Helsinki Declaration and its later amendments.

Patient information. A total of 319 patients who had undergone radical abdominal, vaginal or laparoscopic hysterectomy, with or without salpingo-oophorectomy, and with histopathologically diagnosed adenomyosis or with other pathological conditions, who were diagnosed between January 1, 2014 and August 1, 2017 at the Bağcılar Training and Research Hospital Pathology Laboratory (Istanbul, Turkey), were evaluated in this study.

Epidemiological, clinical and pathological data were retrieved from patient records. For all patients, demographic data including age, presenting symptoms and previous use of tamoxifen, were documented. The criteria for the diagnosis of adenomyosis included the presence of endometrial glands and stroma at a distance of more than one-half of a low-power field $(\sim 2.5 \mathrm{~mm})$ in the myometrium when measured from the lower border of the endometrium $(4,5,14)$. The age distribution of our cases was 30-40, 41-55 and >55 years. Age-dependent physiological changes (endometrial atrophy, basal endometrium, cycle-dependent changes), gestagenic effect alterations, hyperestrogenemic conditions (endometrial polyp, disordered proliferative endometrium, hyperplasia) and carcinomas were evaluated as four different groups. The myometrial characteristics were classified as normal, leiomyoma, carcinoma infiltration, hyperplasia without atypia, atypical hyperplasia in an adenomyotic focus and malignant mesenchymal lesions. In adenocarcinoma cases, tumor grade [according to the International Federation of Gynecology and Obstetrics grading system (15)] depth of myometrial invasion, lymphovascular space involvement, lymph node involvement and tumor stage were determined according to the 8th edition of pTNM staging system (16).

Statistical analysis. The statistical analysis was performed using the Number Cruncher Statistical System 2007 statistical software program. Continous variables were assessed for normality and summarized using mean as appropriate. Differences between categorical variables were assessed using the Chi-squared test, frequency, and percentage distribution of data in addition to definitive statistical methods. $\mathrm{P}<0.05$ was considered to indicate a statistically significant difference.

\section{Results}

Patient characteristics. The mean age \pm standard deviation of the patients who underwent hysterectomy was $52.11 \pm 14.8$ years (range, 28-88 years). Most of the patients (71.79\%) with adenomyosis were aged between 41 and 55 years of age. The patient age and histopathological characteristics of the endo- metrium and myometrium associated with adenomyosis are summarized in Table I. The distribution of endometrial and myometrial characteristics with associated pathological findings according to different age groups is presented in Table II.

Types of endometrial lesions. Endometrial polyps were found in 71 cases, while hyperplasia was present in 9 cases. Simultaneous presence of endometrial polyp and hyperplasia was identified in 6 patients. Disordered proliferative endometrium was observed in 11 patients. Disordered proliferative endometrium, endometrial polyps, and hyperplasia due to hyperestrogenemia were significantly more common among patients aged $41-55$ years old $(\mathrm{P}=0.042)$. Carcinoma was more frequent among patients in the advanced age ( $>55$ years old) group ( $>55$ years; $\mathrm{P}=0.0001$ ). Similar to adenomyosis, leiomyoma was significantly more prevalent in the $41-55$ years age group ( $\mathrm{P}=0.003)$. The two malignant mesenchymal tumors identified were a low-grade endometrial stromal sarcoma and a leiomyosarcoma. Endometrial adenocarcinoma was diagnosed in 32 patients. The age distribution and pathological prognostic parameters of patients with endometrial carcinoma associated with adenomyosis are presented in Table III.

No endometrial carcinoma arising from foci of adenomyosis was observed among our patients. However, infiltration of adenomyotic foci by adenocarcinoma was diagnosed in 3 cases. Atypical endometrial hyperplasia was identified in 2 cases, and hyperplasia without atypia in 1 case. In the only case of dedifferentiated endometrioid carcinoma, the tumor was polypoid and there was no myometrial invasion.

Postoperative treatment and follow-up. Following surgery, the patients received chemotherapy and radiotherapy according to the final pathological stage, if indicated. The mean follow-up period of the 31 patients was 26.4 months (range, 8-44 months). At 38 months, 1 patient was diagnosed with pelvic tumor recurrence. Endometrial carcinoma patient no. 6 succumbed to mortality due to the surgical complications on the 10th postoperative day.

Preoperative findings. The preoperative clinical findings included: abnormal uterine bleeding in 75 patients $(23 \%)$, leiomyoma in $62(19 \%)$, abnormal uterine bleeding due to leiomyoma in $37(11 \%)$, uterine prolapse in $28(8 \%)$, adnexal mass in $25(7.8 \%)$, endometrial carcinoma in $24(7.5 \%)$, cervical lesions (CIN etc.) in 13 (4\%), atypical endometrial hyperplasia in $9(2.8 \%)$, simple endometrial hyperplasia in $9(2.8 \%)$, adenomyosis in $5(1.5 \%)$, pelvic mass in $5(1.5 \%)$, endometrial polyp in $5(1.5 \%)$, leiomyoma and adnexal mass in $5(1.5 \%)$, tamoxifen treatment for breast carcinoma in $5(1.5 \%)$, non-uterine malignancies in $4(1.2 \%)$, adnexal mass with abnormal uterine bleeding in 3 , and leiomyoma and endometrial polyp in 2 patients. Less common findings in three patients included simple endometrial hyperplasia and endometriosis, endometriosis, and cervical stenosis with abnormal uterine bleeding.

\section{Discussion}

Adenomyosis is a common incidental finding that is frequently detected after hysterectomy. The recent advances in diagnostic 
Table I. Distribution of age and pathological findings among patients.

\begin{tabular}{|c|c|c|}
\hline Variables & $\mathrm{n}$ & $\%$ \\
\hline \multicolumn{3}{|l|}{ Age, years } \\
\hline $30-40$ & 9 & 2.82 \\
\hline $41-55$ & 229 & 71.79 \\
\hline$>55$ & 81 & 25.39 \\
\hline \multicolumn{3}{|l|}{ Endometrial findings } \\
\hline $\begin{array}{l}\text { Endometrial atrophy, basal endometrium, } \\
\text { cycle-dependent changes }\end{array}$ & 179 & 56.11 \\
\hline Changes of gestagenic effect & 11 & 3.45 \\
\hline $\begin{array}{l}\text { Endometrial polyp, disordered proliferative } \\
\text { endometrium, endometrial hyperplasia }\end{array}$ & 97 & 30.41 \\
\hline Endometrial carcinoma & 32 & 10.03 \\
\hline \multicolumn{3}{|l|}{ Myometrial findings } \\
\hline Normal myometrium & 133 & 41.69 \\
\hline Leiomyoma & 178 & 55.80 \\
\hline $\begin{array}{l}\text { Carcinoma infiltration and hyperplasia } \\
\text { in adenomyotic foci }\end{array}$ & 6 & 1.88 \\
\hline Malignant mesenchymal lesions & 2 & 0.63 \\
\hline
\end{tabular}

$\mathrm{n}$, patient number.

imaging techniques, such as transvaginal sonography, hysterosalpingography and magnetic resonance imaging have improved the accuracy of the identification of adenomyosis (17). The prevalence of adenomyosis in hysterectomy patients was found to be $16.5 \%$ by Siddegowda et al (18) and was most commonly observed between 31 and 50 years of age. In our study, the youngest patient with adenomyosis was 28 while the oldest was 88 years old. The majority $(71.8 \%)$ of adenomyosis patients belonged to the 41-55 years age group, which was consistent with other studies $(12,19)$.

Stronger and more diffuse cytoplasmic E2 receptor immunoreactivity was detected in the endometrium and myometrium of adenomyotic foci compared with the normal endometrium. Higher concentration of E2, but not P4, were also detected in the serum of adenomyotic cows compared with that of healthy cows (20). In another study, high levels of estrogen were found in the menstrual blood of women with adenomyosis (21). Leyendecker et al suggested that endometriosis and adenomyosis arise from the exaggeration of the basically physiological mechanism of tissue injury and repair, involving local estrogen production (22). Moreover, they suggested that the non-pregnant uterus appear to impose a significant chronic mechanical strain on the subendometrial stromal cells that may lead to local inflammation and proliferation of the basal endometrium into the uterine wall, with the ensuing development of adenomyotic lesions $(22,23)$.

Endometrial cancer (EC) is the most common malignant neoplasm of the female reproductive tract in developed countries (24). The most commonly diagnosed histological subtype is the endometrioid EC (EEC), which is characterized by a lower aggressiveness and a higher long-term disease-free survival following adequate primary and adjuvant treatment compared with that of other histological types of EC (25). Adenomyosis has been documented to coexist with EEC in 16-34\% of the hysterectomy specimens resected for the treatment of EEC. In the present study, the incidence of adenocarcinoma associated with adenomyosis was $10 \%$, which was lower compared with that reported in previous studies, and was more frequent in women aged $>55$ years (26-30). Endometrial polyps, hyperplasia with or without atypia, and adenocarcinoma are also more frequent among women with adenomyosis. Bergholt et al reported a significant association between adenomyosis and endometrial hyperplasia (3). An association between high concentrations of estrogen and adenomyosis, and elevated estrogen concentration in the menstrual blood of women with adenomyosis, were also previously reported $(21,31)$. In addition, relatively high estrogen biosynthesis due to aromatase activity in human adenomyotic tissue has been described, and the high level of estrogen was suggested to contribute to the growth of adenomyosis $(32,33)$. In the present study, lesions such as polyps, disordered proliferative endometrium, or hyperplasia, were found to be associated with hyperestrogenemia in approximately one-third of the patients. Adenomyosis coexisted with polyps, hyperplasia, and adenocarcinoma in 129 cases ( $40.4 \%$ of all the patients). This high ratio indicates the significance of hyperestrogenemia in the development of adenomyosis.

The role of adenomyosis presence in estimating the prognosis of EEC is a subject of debate, despite the fact that the majority of the studies have reported an excellent prognosis for EEC with concomitant adenomyosis due to the lower histological grade and superficial myometrial invasion detected in such cases $(26,27,29)$. Gizzo et al suggested an inverse correlation between myometrial invasion and adenomyosis that may be due to a possible altered adhesion mechanism between the adenomyosis foci and the cancer cells, or by a lower cancer aggressiveness associated with the coexistence of adenomyosis (34). However, there is controversy regarding the role of adenomyosis in EEC, in terms of whether it actively promotes or interferes with myometrial invasion of EC (30). Ismiil et al reported that the presence of adenomyosis in EEC cases may be associated with a poorer prognosis, as it is recognized as a precursor of EEC, and as an enabling factor allowing malignant cells to invade the myometrium by increasing the contact area (35). In the present study, there were three cases of grade 3 adenocarcinomas and one case of dedifferentiated endometrioid carcinoma. The aforementioned adenocarcinomas exhibited a high-to-intermediate differentiation, while high-grade tumors and clear cell carcinomas may occasionally be encountered. These patients had a good clinical prognostic outcome during the follow-up. Our findings suggest that the inflammatory response against tissue injury and the smooth muscle hyperplasia induced by the secreted growth factors may have restricted the expected invasive potential of adenocarcinomas. Similar changes in the microenvironment surrounding the deep adenomyotic foci are responsible for the known complications of endometriosis $(22,23,36-38)$. The longest follow-up duration was 44 months in our patient group, while longer follow-up periods may better delineate patient prognosis. Lymphadenectomy was not performed in a proportion of the patients due to superficial myometrial invasion. Although there was no recurrence in this group of patients, the probability of microinvasion or submicrometastasis cannot be ruled out entirely. 
Table II. Distribution of endometrial and myometrial findings with associated lesions according to age.

\begin{tabular}{|c|c|c|c|c|}
\hline \multirow[b]{2}{*}{ Microscopic findings of the resected specimens } & \multicolumn{4}{|c|}{ Age, years $[\mathrm{n}(\%)]$} \\
\hline & $30-40$ years & 41-55 years & $>55$ years & P-value ${ }^{a}$ \\
\hline \multicolumn{5}{|l|}{ Endometrium } \\
\hline $\begin{array}{l}\text { Endometrial atrophy, basal endometrium, } \\
\text { cycle-dependent changes }\end{array}$ & $6(66.67)$ & $141(61.57)$ & $32(39.51)$ & - \\
\hline Changes of gestagenic effect & $0(0.00)$ & $9(3.93)$ & $2(2.47)$ & 0.826 \\
\hline $\begin{array}{l}\text { Endometrial polyp, DPE and } \\
\text { endometrial hyperplasia }\end{array}$ & $2(22.22)$ & $65(28.38)$ & $30(37.04)$ & 0.042 \\
\hline Endometrial carcinoma & $1(11.11)$ & $14(6.11)$ & $17(20.99)$ & 0.0001 \\
\hline \multicolumn{5}{|l|}{ Myometrium } \\
\hline Normal myometrium & $3(30.00)$ & $82(35.81)$ & $48(60.00)$ & - \\
\hline Leiomyoma & $6(60.00)$ & $143(62.45)$ & $29(36.25)$ & 0.003 \\
\hline $\begin{array}{l}\text { Carcinoma infiltration and hyperplasia-atypical } \\
\text { hyperplasia in adenomyotic focus }\end{array}$ & $1(10.00)$ & $2(0.87)$ & $3(3.75)$ & 0.074 \\
\hline Malignant mesenchymal lesions & $0(0.00)$ & $2(0.87)$ & $0(0.00)$ & 0.357 \\
\hline
\end{tabular}

Adenocarcinoma may involve foci of adenomyosis (39). Koshiyama et al reported that the adenocarcinoma ratio was $16 \%$ in cases of adenomyosis (40). Adenocarcinomas arising from adenomyotic foci were not identified in any of the cases involved in the present study. Kucera et al observed that, in the majority of cases with malignant transformation of adenomyosis, different stages of atypical or hyperplastic changes were simultaneously identified. This observation indicates a similar pathway of carcinogenesis in adenomyosis as in estrogen-responsive endometrial cancer type I (29). In addition, adenocarcinoma infiltration in the adenomyotic foci was observed in three cases, atypical hyperplasia in two cases, and hyperplasia without atypia in one case. Our findings point to the possibility that these lesions may have occured as a primary coincidental neoplasia, rather than the infiltration by adenocarcinoma arising from eutopic endometrium.

For uterine leiomyomas, the factors associated with tumorigenesis may be subdivided into four categories: Predisposing or risk factors, initiators, promoters and effectors. Increased risk may also be associated with early menarche, nulliparity and obesity, whereas decreased risk has been associated with increasing parity and smoking. Risk factors for fibroids may achieve significance through their contribution to either the initiation or the progression of tumorigenesis. Although their impact often appears to be due to their effects on estrogen and progesterone, other mechanisms may also be involved. Estrogen and progesterone are promoters of fibroid growth acting synergistically (41). Several studies have reported that the mRNA and protein expression levels of estrogen receptor- $\alpha$ and $-\beta$ are higher in leiomyoma compared with those in normal myometrium $(42,43)$. The levels of several growth factors and their receptors are increased in fibroids. Growth factors may be the mediators or effectors of sex steroid upregulation, while a primary dysregulation of one or more growth factors must also be considered (41). Adenomyosis is common in hysterectomy specimens of patients with concurrent fibroids. The reported incidence of concurrent fibroids is $19-57 \%(2,6,7,44-46)$. In a study by Shrestha et al on 150 patients, $52 \%$ had adenomyosis without fibroids, $18 \%$ had both adenomyosis and fibroids, and $30 \%$ had only fibroids (47). In a large series, adenomyosis was diagnosed histologically in $8 \%$ of the cases, while concomitant adenomyosis and leiomyomas were diagnosed histologically in $20 \%$ of the patients. Of the patients with adenomyosis, $70 \%$ were premenopausal (48). In the present study, adenomyosis was associated with leiomyoma in 55\% of the cases. This incidence was notably higher compared with that reported by previous studies, indicating that pathogenetic factors may be similar between adenomyosis and leiomyoma, mainly in patients aged 41-55 years.

Based on clinical reports, tamoxifen appears to be a crucial risk factor. Tamoxifen exerts anti-estrogenic effects on the breast through a complex mechanism. It also exerts estrogenic effects on other tissues, including the endometrium. This agent is widely used in the treatment of breast cancer and chemoprevention in high-risk pre- and postmenopausal women. Tamoxifen has been shown to cause adverse effects at the uterine level, the most serious being endometrial carcinoma and uterine sarcoma (49). Tamoxifen is an antagonist of the estrogen receptor in breast tissue. Via its active metabolite, hydroxytamoxifen, it acts like an agonist leading to development or reactivation of adenomyosis (50). Adenomyosis occurs more commonly than is generally realized in women using tamoxifen, and may account for the postmenopausal bleeding in women treated with this agent for breast cancer (51-53). Bleeding occurs more frequently among women with endometrial hyperplasia, endometrial carcinoma, or those who use tamoxifen (3). A total of five patients in our study had a history of tamoxifen treatment. The abovementioned data and our findings indicate that estrogen plays a key role in the pathogenesis of adenomyosis. 
Table III. Histopathologic parameters for prognosis of adenocarcinoma cases.

\begin{tabular}{|c|c|c|c|c|c|c|c|}
\hline Case no. & Age, years & Tumor grade & MI, \% & LVSI & LNI & Stage (TNM) & Recurrence \\
\hline 1 & 44 & 2 & $<50$ & + & PWL & $\mathrm{p}(\mathrm{T} 1 \mathrm{aNxMx})$ & - \\
\hline 2 & 50 & 2 & $>50$ & - & 0 & $\mathrm{p}(\mathrm{T} 2 \mathrm{~N} 0 \mathrm{Mx})$ & - \\
\hline 3 & 56 & 1 & $<50$ & - & PWL & $\mathrm{p}(\mathrm{T} 1 \mathrm{aNxMx})$ & - \\
\hline 4 & 50 & 2 & $<50$ & - & 0 & $\mathrm{p}(\mathrm{T} 1 \mathrm{aN} 0 \mathrm{Mx})$ & - \\
\hline 5 & 61 & 2 & $<50$ & - & 0 & $\mathrm{p}(\mathrm{T} 1 \mathrm{aNOMx})$ & - \\
\hline 6 & 71 & 3 & $>50$ & - & 0 & $\mathrm{p}(\mathrm{T} 1 \mathrm{bN} 0 \mathrm{Mx})$ & Deceased \\
\hline 7 & 66 & 2 & $<50$ & - & 0 & $\mathrm{p}(\mathrm{T} 1 \mathrm{aN} 0 \mathrm{Mx})$ & - \\
\hline 8 & 72 & 2 & $>50$ & + & 0 & $\mathrm{p}(\mathrm{T} 1 \mathrm{bN} 0 \mathrm{Mx})$ & - \\
\hline 9 & 48 & 1 & $<50$ & - & 0 & $\mathrm{p}(\mathrm{T} 1 \mathrm{aN} 0 \mathrm{Mx})$ & - \\
\hline 10 & 34 & 1 & - & - & PWL & $\mathrm{p}(\mathrm{T} 1 \mathrm{aNxMx})$ & - \\
\hline 11 & 52 & 2 & $<50$ & + & 0 & $\mathrm{p}(\mathrm{T} 1 \mathrm{aN} 0 \mathrm{Mx})$ & Pelvic \\
\hline 12 & 46 & 2 & - & - & 0 & $\mathrm{p}(\mathrm{T} 1 \mathrm{aN} 0 \mathrm{Mx})$ & - \\
\hline 13 & 65 & $\begin{array}{l}\text { Dedifferentiated } \\
\text { endometrioid } \mathrm{Ca}\end{array}$ & - & - & 0 & $\mathrm{p}(\mathrm{T} 1 \mathrm{aN} 0 \mathrm{Mx})$ & - \\
\hline 14 & 68 & 1 & $>50$ & - & PWL & $\mathrm{p}(\mathrm{T} 1 \mathrm{bNxMx})$ & - \\
\hline 15 & 48 & 1 & $<50$ & - & PWL & $\mathrm{p}(\mathrm{T} 1 \mathrm{aNxMx})$ & - \\
\hline 16 & 42 & 1 & $<50$ & - & PWL & $\mathrm{p}(\mathrm{T} 1 \mathrm{aNxMx})$ & - \\
\hline 17 & 62 & 2 & $>50$ & - & 1 & $\mathrm{p}(\mathrm{T} 1 \mathrm{bN} 1 \mathrm{aMx})$ & - \\
\hline 18 & 61 & 1 & - & - & PWL & $\mathrm{p}(\mathrm{T} 1 \mathrm{aNxMx})$ & - \\
\hline 19 & 56 & 3 & $<50$ & + & PWL & $\mathrm{p}(\mathrm{T} 1 \mathrm{aNxMx})$ & - \\
\hline 20 & 58 & 2 & $>50$ & + & PWL & $\mathrm{p}(\mathrm{T} 1 \mathrm{bNxMx})$ & - \\
\hline 21 & 66 & Clear cell $\mathrm{Ca}$ & $<50$ & - & 0 & $\mathrm{p}(\mathrm{T} 1 \mathrm{aN} 0 \mathrm{Mx})$ & - \\
\hline 22 & 56 & 1 & $<50$ & - & PWL & $\mathrm{p}(\mathrm{T} 1 \mathrm{aNxMx})$ & - \\
\hline 23 & 57 & 1 & $<50$ & - & PWL & $\mathrm{p}(\mathrm{T} 1 \mathrm{aNxMx})$ & - \\
\hline 24 & 49 & 2 & $<50$ & - & PWL & $\mathrm{p}(\mathrm{T} 1 \mathrm{aNxMx})$ & - \\
\hline 25 & 62 & 1 & $<50$ & - & 0 & $\mathrm{p}(\mathrm{T} 1 \mathrm{aN} 0 \mathrm{Mx})$ & - \\
\hline 26 & 51 & 1 & $<50$ & - & PWL & $\mathrm{p}(\mathrm{T} 1 \mathrm{aNxMx})$ & - \\
\hline 27 & 43 & 2 & $<50$ & - & PWL & $\mathrm{p}(\mathrm{T} 1 \mathrm{aNxMx})$ & - \\
\hline 28 & 51 & 1 & $<50$ & - & PWL & $\mathrm{p}(\mathrm{T} 1 \mathrm{aNxMx})$ & - \\
\hline 29 & 53 & $\begin{array}{l}\text { Mixed } \mathrm{Ca} \text { (endometrioid } \\
+ \text { clear cell } \mathrm{Ca})\end{array}$ & $>50$ & - & 1 & Yp (T2N1aMx) & - \\
\hline 30 & 57 & 1 & $<50$ & - & PWL & $\mathrm{p}(\mathrm{T} 1 \mathrm{aNxMx})$ & - \\
\hline 31 & 72 & 2 & $>50$ & - & PWL & $\mathrm{p}(\mathrm{T} 1 \mathrm{bNxMx})$ & - \\
\hline 32 & 62 & 3 & $<50$ & + & PWL & $\mathrm{p}(\mathrm{T} 1 \mathrm{aNxMx})$ & - \\
\hline
\end{tabular}

TNM, TNM Classification of Malignant Tumours; MI, myometrial invasion; LVSI, lymphovascular space involvement; LNI, lymph node involvement; PWL, patient without lymph node dissection; Ca, carcinoma.

Although this pathological entity has long been known, reliable epidemiological studies are scarce, since the diagnosis of adenomyosis was only possible postoperatively in the past. The majority of symptomatic women treated for adenomyosis are in the fourth or fifth decades of life and multiparous (52). The initial symptoms of adenomyosis are non-specific and may also be observed in a number of other disorders, such as dysfunctional uterine bleeding, leiomyomas and endometriosis. In a study by Mehla et al, adenomyosis was the most frequent cause of abnormal uterine bleeding. The overall incidence of adenomyosis was $46.78 \%$, leiomyoma was found in $39.9 \%$, while both coexisted in $13.30 \%$ of the cases (54). Isaoğlu et al reported that $30.23 \%$ of the hysterectomy cases were diagnosed as adenomyosis, whereas leiomyoma was observed in $28.19 \%$ of the hysterectomies performed for abnormal uterine bleeding (55). Weiss et al concluded that adenomyosis is mostly an incidental finding and may not be the source of symptomatology for women undergoing hysterectomy (6). In the present study, the most frequent (23\%) preoperative symptom was abnormal uterine bleeding. In addition, only hysterectomy specimens following surgery for lesions coexisting with adenomyosis were evaluated; therefore, this was not an epidemiological study.

The most crucial factor in the pathogenesis of adenomyosis appears to be hyperestrogenemia. In conclusion, a meticulous evaluation and screening should be performed for 
adenomyosis, particularly in patients in the fourth and fifth decades of life, in addition to leiomyoma. Radiological assessment is initially recommended for such patients to detect the extent of the lesions (focal or diffuse) and/or their severity, in order to determine the treatment options for each individual patient. Following hormonal therapy, surgery may be performed according to the treatment response. Although the EC cases associated with adenomyosis had a good prognosis, clinicians should bear in mind that tumors with an aggressive morphology may be occasionally encountered. The tissue reaction developing around the adenomyotic foci may restrict the invasive potential of adenocarcinomas, thereby accounting for the better clinical course and prognostic outcomes in these cases.

\section{Acknowledgements}

Not applicable.

\section{Funding}

No funding was received.

\section{Availability of data and materials}

The data generated and analyzed in the present study are available from the corresponding author upon reasonable request.

\section{Authors' contributions}

ST designed the present study, performed pathological analysis, collected the pathological data and wrote the manuscript. EÇ performed data and statistical analyses. HT collected the pathological data. TÇ contributed to the pathological data analysis. SI performed patient follow-up analyses. ATU acquired patient data and performed data analysis. All the authors have read and approved the final version of this manuscript.

\section{Ethics approval and consent to participate}

Prospective ethical approval (2017/\#604 Project) was obtained from the Human Research Ethics Commitee at the Bagcilar Training and Research Hospital. The research was conducted in accordance with the ethical standarts laid down in the 1964 Helsinki Declaration and its later amendments.

\section{Patient consent for publication}

Not applicable.

\section{Competing interests}

The authors declare that they have no competing interests.

\section{References}

1. Bird CC, McElin TW and Manalo-Estrella P: The elusive adenomyosis of the uterus-revisited. Am J Obstet Gynecol 112: 583-593, 1972

2. Mehasseb MK and Habiba MA: Adenomyosis uteri: An update. Obstet Gynaecol 11: 41-47, 2009.
3. Bergholt T, Eriksen L, Berendt N, Jacobsen M and Hertz JB: Prevalence and risk factors of adenomyosis at hysterectomy. Hum Reprod 16: 2418-2421, 2001.

4. Shrestha A, Shrestha R, Sedhai LB and Pandit U: Adenomyosis at hysterectomy: Prevalence, patient characteristics, clinical profile and histopathological findings. Kathmandu Univ Med J (KUMJ) 10: 53-56, 2012.

5. Parazzini F, Mais V, Cipriani S, Busacca M and Venturini P GISE: Determinants of adenomyosis in women who underwent hysterectomy for benign gynecological conditions: Results from a prospective multicentric study in Italy. Eur J Obstet Gynecol Reprod Biol 143: 103-106, 2009.

6. Weiss G, Maseelall P, Schott LL, Brockwell SE, Schocken M and Johnston JM: Adenomyosis a variant not a disease? Evidence from hysterectomized menopausal women in the SWAN study. Fertil Steril 91: 201-206, 2009.

7. Molitor JJ: Adenomyosis: A clinical and pathological appraisal Am J Obstet Gynecol 110: 275-284, 1971.

8. Vercellini P, Parazzini F, Oldani S, Panazza S, Bramante T and Crosignani PG: Adenomyosis at hysterectomy: A study on frequency distribution and patient characteristics. Hum Reprod 10: 1160-1162, 1995.

9. Yeniel O, Cirpan T, Ulukus M, Ozbal A, Gundem G, Ozsener S, Zekioglu $\mathrm{O}$ and Yilmaz H: Adenomyosis: Prevalence, risk factors, symptoms and clinical findings. Clin Exp Obstet Gynecol 34: 163-167, 2007.

10. Gordts S, Brosens JJ, Fusi L, Benagiano G and Brosens I: Uterine adenomyosis: A need for uniform terminology and consensus classification. Reprod Biomed Online 17: 244-248, 2008.

11. Azziz R: Adenomyosis: Current perspectives. Obstet Gynecol Clin North Am 16: 221-235, 1989.

12. Dayal S and Nagrath A: Pattern and frequency of endometrial and ovarian pathologies with adenomyosis uteri in patients who attended the tertiary care hospital among rural population of North India. MAMC J Med Sci 1: 147-150, 2015.

13. Arunachalam B and Manivasakan J: A clinico-pathological study of adenomyosis. J Clin Diagnos Res 6: 428-430, 2012.

14. Uduwela AS, Perera MA, Aiqing L and Fraser IS: Endometrial-myometrial interface: Relationship to adenomyosis and changes in pregnancy. Obstet Gynecol Surv 55: 390-400, 2000.

15. Creasman W, Odicino F, Maisonneuve P, Beller U, Benedet JL, Heintz AP, Ngan HY, Sideri M and Pecorelli S: Carcinoma of the corpus uteri: FIGO annual report. J Epidemiol Biostat 6: 47-86, 2001.

16. Brierley JD, Gospodarowicz MK and Wittekind C (eds): TNM Classification of Malignant Tumors. 8th edition. Oxford, UK, Wiley, 2016.

17. Di Spiezio Sardo A, Calagna G, Santangelo F, Zizolfi B, Tanos V, Perino A and De Wilde RL: The role of hysterescopy in the diagnosis and treatment of adenomyosis. Biomed Res Int 2017: Article ID 2518396, 2017.

18. Siddegowda MS, Manjunath MR and Shivakumar S: Occurrence of Adenomyosis in Hysterectomy Specimen and its Clinical Correlation in a Tertiary Care Hospital in Mandya, Karnataka, India. Inter J Sci Study 3: 61-64, 2015.

19. Anwar A: Incidence of adenomyosis in hysterectomies. Pak J Med Res 44: 38-40, 2005.

20. Korzekewa AJ, Bah MM, Gestwicka M, Socha B and Skarżyński DJ: Adenomyosis in the bovine uterus: Correlation between frequency, age, and $17 \beta$-estradiol-progesterone equilibrium. Theriogenology 79: 165-172, 2013.

21. Takahashi K, Nagata $H$ and Kitao M: Clinical usefulness of determination of estradiol levels in the menstrual blood for patients with adenomyosis. Nihon Sanka Fujinka Gakkai Zasshi 41: 1849-1850, 1989.

22. Leyendecker G, Wildt I and Mall G: The pathophysiology of endometriosis and adenomyosis: Tissue injury and repair. Arch Gynecol Obstet 280: 529-538, 2009.

23. Leyendecker G and Wildt L: A new concept of endometriosis and adenomyosis: Tissue injury and repair (TIAR). Horm Mol Biol Clin Investig 5: 125-142, 2011.

24. Siegel RL, Miller KD and Jemal A: Cancer statistics, 2015. CA Cancer J Clin 65: 5-29, 2015.

25. Prat J: Prognostic parameters of endometrial carcinoma. Hum Pathol 35: 649-662, 2004.

26. Mittal KR and Barwick KW: Endometrial adenocarcinoma involving adenomyosis without true myometrial invasion is characterized by frequent preceding estrogen therapy, low histologic grades, and excellent prognosis. Gynecol Oncol 49: 197-201, 1993. 
27. Jacques SM and Lawrence WD: Endometrial adenocarcinoma with variable-level myometrial involvement limited to adenomyosis: A clinicopathologic study of 23 cases. Gynecol Oncol 37: 401-407, 1990

28. Hernandez E and Woodruff JD: Endometrial adenocarcinoma arising in adenomyosis. Am J Obstet Gynecol 138: 827-832, 1980.

29. Kucera E, Hejda V, Dankovcik R, Valha P, Dudas M and Feyereisl J: Malignant changes in adenomyosis in patients with endometrial adenocarcinoma. Eur J Gynecol Oncol 32: 182-184, 2011.

30. Ismiil N, Rasty G, Ghorab Z, Nofech-Mozes S, Bernardini M, Ackerman I, Thomas G, Covens A and Khalifa MA: Adenomyosis involved by endometrial adenocarcinoma is a significant risk factor for deep myometrial invasion. Ann Diagn Pathol 11: 252-257, 2007.

31. Parazzini F, Vercellini P, Panazza S, Chatenoud L, Oldani S and Crosignani PG: Risk factors for adenomyosis. Hum Reprod 12 1275-1279, 1997.

32. Urabe M, Yamamoto T, Kitawaki J, Honjo $\mathrm{H}$ and Okada $\mathrm{H}$ : Estrogen biosynthesis in human uterine adenomyosis. Acta Endocrinol (Copenh) 121: 259-264, 1989.

33. Yamamato T, Noguchi T, Tamura T, Kitawaki J and Okada $\mathrm{H}$ : Evidence for estrogen synthesis in adenomyotic tissues. Am J Obstet Gynecol 169: 734-738, 1993.

34. Gizzo S, Patrelli TS, Dall'asta A, DI Gangi S, Giordano G, Migliavacca C, Monica M, Meriso C, Nardelli GB, Quranta M, et al: Coexistence of adenomyosis and endometrioid endometrial cancer: Role in surgical guidance and prognosis estimation. Oncol Lett 11: 1213-1219, 2016.

35. Ismiil N, Rasty G, Ghorab Z, Nofech-Mozes S, Bernardini M, Thomas G, Ackerman I, Covens A and Khalifa MA: Adenomyosis is associated with myometrial invasion by FIGO1 endometrial adenocarcinoma. Int J Gynecol Pathol 26: 278-283, 2007.

36. Koike N, Tsunemi T, Uekuri C, Akasaka J, Ito F, Shigemitsu A and Kobayashi H: Pathogenesis and malignant transformation of adenomyosis (Review). Oncol Rep 29: 861-867, 2013.

37. Walter I, Handler J, Reifinger M and Aurich C: Association of endometriosis in horses with differentiation of periglandular myofibroblasts and changes of extracellular matrix proteins. Reproduction 121: 581-586, 2001.

38. Van Kaam KJ, Schouten JP, Nap AW, Dunselman GA and Groothuis PG: Fibromuscular differentiation in deeply infiltrating endometriosis is a reaction of resident fibroblasts to the presence of ectopic endometrium. Hum Reprod 23: 2692-2700, 2008.

39. Hall JB, Young RH and Nelson JH Jr: The prognostic significance of adenomyosis in endometrial carcinoma. Gynecol Oncol 17: 32-40, 1984.

40. Koshiyama M, Okamoto T and Ueta M: The relationship between endometrial carcinoma and coexistent adenomyosis uteri, endometriosis externa and myoma uteri. Cancer Detec Prev 28: 94-98, 2004.
41. Flake GP, Andersen J and Dixon D: Etiology and pathogenesis of uterine leiomyomas: A review. Environ Health Perspect 111: 1037-1054, 2003.

42. Benassayag C, Leroy MJ, Rigourd V, Robert B, Honoré JC, Mignot TM. Vacher-Lavenu MC, Chapron $C$ and Ferré F: Estrogen receptors (ERalpha/ERbeta) in normal and pathological growth of the human myometrium: Pregnancy and leiomyoma. Am J Physiol 276: E1112-E1118, 1999.

43. Kovács KA, Oszter A, Göcze PM, Környei JL and Szabó: Comparative analysis of cyclin D1 and oestrogen receptor (alpha and beta) levels in human leiomyoma and adjacent myometrium. Mol Hum Repr 7: 1085-1091, 2001.

44. Shaikh H and Khan KS: Adenomyosis in Pakistani women: Four year experience at the Aga Khan University Medical centre, Karachi. J Clin Pathol 43: 817-819, 1990.

45. Leyendecker G, Kunz G, Kissler S and Wildt L: Adenomyosis and reproduction. Best Pract Res Clin Obstet Gyneacol 20: 523-546, 2006.

46. Mathur BB, Shah BS and Bhende YM: Adenomyosis uteri. A pathologic study of 290 cases. Am J Obstet Gynecol 84: 1820-1829, 1962.

47. Shrestha A and Sedai LB: Understanding clinical features of adenomyosis: A case control study. Nepal Med Coll J 14: 176-179, 2012.

48. Wallwiener M, Taran FA, Rothmund R, Kasperkowiak A, Auwärter G, Ganz A, Kraemer B, Abele H, Schönfisch B, Isaacson KB and Brucker SY: Laparoscopic supracervical hysterectomy (LSH) versus total laparoscopic hysterectomy (TLH): An implementation study in 1,952 patients with an analysis of risk factors for conversion to laparotomy and complications, and of procedure-specific re-operations. Arch Gynecol Obstet 288: 1329-1339, 2013

49. Polin SA and Ascher SM: The effect of tamoxifen on the genital tract. Cancer Imaging 8: 135-145, 2008.

50. Deligdisch L: Effects of hormone therapy on the endometrium. Mod Pathol 6: 94-106, 1993.

51. Cohen I, Beyth Y, Tepper R, Figer A, Shapira J, Cordoba M, Yigael D and Altaras MM: Adenomyosis in postmenopausal breast cancer patients treated with tamoxifen: A new entity? Gynecol Oncol 58: 86-91, 1995.

52. Taran FA, Stewart EA and Brucker S: Adenomyosis: Epidemiology, risk factors, clinical phenotype and surgical and interventional alternatives to hysterectomy. Geburtshilfe Frauenheilkd 73: 924-931, 2013.

53. McCluggage WG, Desai V and Manek S: Tamoxifen-associated postmenopausal adenomyosis exhibits stromal fibrosis, glandular dilatation and epithelial metaplasias. Histopathology 37: 340-346, 2000

54. Mehla S, Singh M and Chutani N: Clinicopathological correlation of adenomyosis and leiomyoma in hysterectomy specimens as the cause of abnormal uterine bleeding: A retrospective study. Sch J App Med 2: 3320-3323, 2014.

55. İsaoğlu U, Yılmaz M, Delibaş I, Gözükara I, Bilici AE, Uluğ P and Kabalar E: The Evaluation of histopathologic diagnosis in specimens of hysterectomy. Abant Med J 2: 91-94, 2013. 